\title{
SÔBRE AS PARAPLEGIAS CIFOSCOLIÓTICAS. TRATAMENTO NEUROCIRÚRGICO
}

\author{
Roberto Melaragno Filmo * \\ Marino Lazzareschi ** \\ Rolando A. Thinuto***
}

O sofrimento medular como conseqüência de cifoscolioses congênitas é eventualidade extraordinàriamente rara $\mathrm{e}$ seu mecanismo tem sido objeto de controvérsias entre os autores que tiveram a oportunidade de observar êsses casos. Na literatura brasileira, desconhecemos qualquer publicação prévia de paraplegias cifoscolióticas, com exceção de um caso de compressão medular por cifoscoliose em paciente com doença de Friedreich, apresentado à Seç̧ão de Neuropsiquiatria da Associação Paulista de Medicina, por Paulo Pinto Pupo e col. ${ }^{1}$. Esse paciente, no entanto, não foi submetido a intervenção cirúrgica. Segundo Hyndman ${ }^{2}$, a raridade com que as escolioses se acompanham de sinais medulares poderia ser explicada pela $\mathrm{fa}$ culdade do tecido nervoso em se ajustar às modificações insidiosas da forma, à compressão e aos estiramentos.

Excluídos os casos de cifoscolioses adquiridas (paralíticas, joóticas, raquíticas, etc.), surpreende a muito maior incidência de fenômenos medula. res no período de ritmo de crescimento orgânico mais rápido. Assin, de acôrdo com os dados coligidos por Pais ${ }^{3}$, observa-se a seguinte distribuição percentual de paraplegias cifoscolióticas, de acôrdo com a idade: $65 \%$ na segunda década, sendo $40 \%$ entre os 15 e 20 anos; $15 \%$ na terceira decada; $6 \%$ na primeira e, finalmente, apenas $4 \%$ na quinta década da vida. Ainda segundo o mesmo autor, que realizou excelente revisão crítica do conjunto dos casos publicados na literatura, $70 \%$ das paraplegias decorrentes diretamente de cifoscoliose acometem pacientes do sexo masculino. Habitualmente, a sede da cifoscoliose é a região dorsal; com menor freqüência, a localização do processo pode ser verificada na coluna lombar. Em $74 \%$ dos casos, a cifoscoliose é sinistro-convexa, em geral de curvatura de curto raio, cujo ápice se situa, comumente, entre a $4 .^{\mathrm{a}} \mathrm{e}$ a $9 .^{\mathrm{a}}$ vértebras dorsais. A curva principal é acompanhada, quase sempre, de curvas de compensação, mais ou menos desenvolvidas, assim como de componentes de torção da coluna.

Trabalho apresentado ao Departamento de Neuro-Psiquiatria da Associação Paulista de Medicina, em 19 abril 1950 e à Sociedade Brasileira de Ortopedia e Traumatologia, Regional de São Paulo, em 21 abril 1950.

* Assistente de Neurologia da Fac. Med. da Úniv. de São Paulo (Prof. A. Tolosa) e Neurologista do I.A.P.E.T.C. de S. Paulo.

* Chefe do Serviço de Ortopedia do I.A.P.E.T.C. de Săo Paulo.

*** Neurocirurgião do Hospital das Clínicas e do I.A.P.E.T.C. de São Paulo. 
A fisiopatologia dos distúrbios medulares na vigência de cifoscoliose congênita ainda é objeto de desacôrdo. Das várias teorias propostas, a primeira atribui a compressão medular ao tecido adiposo excessivanmente desenvolvido no espaço epidural. Realmente, com muita freqüência - - de que nosso caso é um exemplo - um pelotão de gordura é encontrado pelo cirurgião no espaço epidural. Entretanto, sua existência não é constante e, mesmo quando presente, o tecido gorduroso não parece suficiente para determinar compressão da medula espinal. Esse acúmulo de gordura foi interpretado por alguns autores como conseqüência de um processo hiperplástico ex-vacuo, enquanto que, para outros, estaria relacionado a distúrbios da circulação venosa intra-raquidiana. Parece-nos mais provável que tais lóbulos adiposos, por vêzes infiltrados de pequenas zonas hemorrágicas, nada mais sejam do que o conjunto de gordura de tôda a superfície epidural da região, impelida em massa para trás, devido ao achatamento da dura-máter contra a convexidade óssea da cifoscoliose. De qualquer forma, a extirpação pura e simples da massa gordurosa epidural, em algumas laminectomias, em nada influiu no sofrimento medular existente. Verdade é que, eventualmente, êsse tecido se inflama, constituindo-se então uma epidurite (caso de Rouques e col.4).

André-Thomas e col. ${ }^{5}$ invocam outro mecanismo explicativo da lesão medular, baseados na observação durante as laminectomias dêsses pacientes. Assim, desde que o espaço subdural é desembaraçado do tecido gorduroso, nota-se a falta de batimentos da dura-máter. Logo que esta é aberta, em vários casos, a medula se hernia ou, pelo menos, os lábios da incisão se abrem. No caso de André-Thomas e col. a medula se encontrava distendida sôbre a angulação da cifoscoliose como uma corda de violino sôbre o cavalete. Para André-Thomas, além da angulação da medula contra a face anterior da dura-máter, agiria ainda a tensão dos cordões radiculares estirados, que vão aplicar a dura-máter fortemente distendida contra a face posterior da medula. Assim, além da ação direta sôbre o tecido nervoso, vai-se produzir compressão dos vasos medulares e a isquemia resultante explica as alterações circulatórias, sangüíneas e linfáticas, e o edema medular observado durante as intervenções ou nas autópsias. Como corolário desta teoria, impõe-se o princípio da não suturação da dura-máter após o término da intervenção, técnica essa seguida hoje pela quase totalidade dos neurocirurgiōes. Esse mecanismo, no entanto, não é suficiente para explicar a totalidade dos casos. Realmente, Dereux e col. ${ }^{6}$ registram um caso anátomo-clínico de paraplegia cifoscoliótica, devido à compressão direta da medula pelo esporão ósseo representado por uma vértebra cuneiforme $\left(T_{2}\right)$. Essas vértebras triangulares são quase sempre anormalmente móveis e o disco intervertebral pode-se herniar excessivamente.

Além da ação compressiva no sentido transversal, da dura-máter sôbre a medula, devemos considerar uma outra ação no sentido longitudinal, do envoltório dural, sòlidamente fixado cranialmente no orifício occipital e caudalmente no sacro. Explica-se assim o motivo pelo qual a maior incidência dos sofrimentos medulares se verifica entre os 15 e 20 anos de vida, justa- 
mente na época do crescimento mais rápido do indivíduo. Finalmente, como Pais ${ }^{3}$ muito bem esclarece, a torção das vértebras desempenha também papel patogênico para o desencadear da lesão medular. De fato, em uma cifoscoliose de discreta gravidade, os eixos transversais que passam pelos orifícios de conjugação podem rodar $90^{\circ}$ ao nível do ápice da curvatura. A isto devemos acrescentar as rotações em sentido contrário, nas curvas de compensação acima e abaixo da deformidade principal; isto é, cêrca de $40^{\circ}$ de rotação acima e $60^{\circ}$ abaixo, o que dá uma torção final de $190^{\circ}$ para uma cifosciolise de mediana gravidade.

Vemos, pois, que diversos mecanismos podem ser responsalilizados como fatôres patogênicos de paraplegia cifoscoliótica. Queremos crer, com Borchardt ${ }^{7}$, que êsses diversos mecanismos podem agir associadamente para lesar a medula.

Quanto à sintomatologia neurológica, não há distinção essencial com a de uma compressão medular de qualquer outra etiologia. Contudo, é interessante notar a possibilidade de existência de fenômenos supra-lesionais, sobretudo vestibulares $\left(\right.$ Chavany $\left.^{8}\right)$. Barré e col. ${ }^{9}$ descreveram como distúrbios cardinais em um paciente com paraplegia cifoscoliótica, alterações do equilíbrio atribuiveis principalmente a perturbações vestibulares (comprovadas pela anormalidade das reações instrumentais) e, acessòriamente, à paresia dos músculos dos membros inferiores, aos distúrbios da sensibilidade profunda e, finalmente, aos distúrbios da repartição ponderal, em virtude das deformações da coluna vertebral.

Observação - L. V. R., 17 anos, masculino, branco, ajudante de mecânico, brasileiro. Reg. I.A.P.E.T.C. 11.118-00. O paciente veio consultar urn de nós (RMF) em 10 de novembro de 1949, no Ambulatório de Neurologia do I.A.P.E.'I.C., acusando paralisia e embotamento da sensibilidade em ambos os membros inferiores. Sempre fôra sadio e, estranhamente, jamais fôra observado qualquer desvio da coluna vertebral. Suas primeiras perturbações tiveram início de modo brusco, há cêrca de 18 meses. Transportava uma prancha pesada sôbre a cabeça, no meio de uma fila de três e, ao projetá-la para o chão, no lado direito, atrasou-se a seus companheiros, sentindo então dôres violentíssimas na região lombar; o tronco ficou girado para a direita, impossibilitado de se endireitar e, apenas a muito custo, reassumiu a posição normal. Foi encaminhado a uma Companhia de Seguros, onde lhe foi prescrita uma série de massagens, com as quais as dôres cederam e o paciente reassumiu seu serviço. Por dois ou três meses, passou relativamente bem, com algumas dôres vagas e suportáveis nas costas; após êsse prazo, no entanto, as dôres voltaram a se acentuar e só então percebeu um pronunciado desvio da coluna, na parte alta do tórax; com o tempo, teve a impressão que êsse desvio se acentuava. Há aproximadamente um ano, procurou o Ambulatório de Ortopedia do I.A.P.E.T.C., onde lhe foi prescrito o uso de colete ortopédico. Entretanto, o doente só veio a usá-lo 3 meses depois, permanecendo com êle, mesmo durante o trabalho, por cêrca de dois meses. Aos poucos, começou a perceber fraqueza progressiva em ambos os membros inferiores, que determinou inúmeras quedas. Retirado o colete, as dôres não mais o incomodaram, mas, por outro lado, as pernas se tornaram cada vez mais fracas. Aos poucos e paralelamente, notou certo embotamento da sensibilidade dos membros inferiores. Jamais teve distúrbios de esfíncter, nem de potência coeundi; nunca apresentou escaras de decúbito. Os membros superiores nunca foram afetados, conservando íntegras sua motricidade e sensibilidade. Não há casos semelhantes em pessoas 
de sua família. O exame clínico geral e o dos aparelhos circulatório e respiratório nada evidenciou de anormal.

Exame ortopédico - Ombro direito mais alto que o esquerdo; região supraclavicular direita em nível mais elevado que a esquerda e de maior amplitude; fossa infraclavicular direita mais escavada que a esquerda; desaparecimento do triângulo tóraco-pélvico-braquial à esquerda; tronco inclinado para a direita, sendo a inclinação bem apreciada através da linha esternal; deformação acentuada da região esternal ao nível do ângulo de Luys, na metade esquerda; rebordo costal à direita mais baixo que à esquerda; coluna cervical desviada para a esquerda; cristas ilíacas à mesma altura; na região supra-espinhosa direita nota-se uma saliência acentuada, estando a região também em nível mais alto que à esquerda, cêrca de $4 \mathrm{~cm}$, enquanto a região supra-espinhosa esquerda se mostra ligeiramente escavada; cifose dorsal alta; escoliose dorsal média dextro-convexa e ligeira escoliose dorsolombar sinistroconvexa. Ângulo da omoplata direita mais saliente e em nível mais alto que o esquerdo, estando êste sôbre a linha espondílica e aquêle afastado da mesma linha cêrca de $6 \mathrm{~cm}$. Região infra-espinhosa esquerda aplainada, enquanto à direita se apresenta levemente abaulada. A flexão do tronco reduz ligeiramente a escoliose dorsolombar, permanecendo inalterada a cifoscoliose dorsal alta. Nesta posição nota-se uma regular protuberância no hemitórax direito (giba costal). Com as mudanças de posição não se observam alterações apreciáveis. Palpação e percussão indolores. Com exceção da coluna dorsal, que se apresenta rígida e com deformidades irredutíveis às manobras manuais, os demais segmentos apresentam-se com movimentos livres $e$ indolores.

Examo neurológico - Psiquismo íntegro. Impossibilidade de se manter de pé pela completa paralisia dos membros inferiores. Pesquisa do sinal de Romberg, portanto, prejudicada. Nos membros inferiores, há apenas a possibilidade de debilíssimos movimentos de flexão e extensão dos grandes artelhos; paralisia dos músculos paravertebrais lombares e de ambos os psoas illacos; fôrça muscular íntegra nos membros superiores. Membros inferiores com ligeiro aumento da passividade e da extensibilidade. Hiperreflexia profunda nos membros inferiores, principalmente dos reflexos aquileus. Não há Rossolimo nem Mendel Bechterew. Sinal de Babinski esboçado de ambos os lados. Clono dos pés. Acentuada hipoestesia táctil, térmica $\mathrm{e}$ dolorosa até o nível de $\mathrm{T}_{8}$. Entre $\mathrm{T}_{8}$ e $\mathrm{T}_{10}$, aproximadamente, essa hipoestesia é muito menos acentuada. Abatiestesia nos membros inferiores; apalestesia até as espinhas ilíacas ântero-superiores, inclusive. Nervos cranianos indenes. Ausência de escaras. de decubito e de distúrbios esfinctéricos.

Exame do líqüido cefalorraquidiano - Punção lombar; às provas manométricas foi verificado bloqueio completo do canal raquidiano; líquidido límpido e levemente xantocrômico (índice ictérico 0,1 ). Citometria 0,8 cel por $\mathrm{mm}^{3}$; proteínas totais $1,45 \mathrm{~g}$ por litro; cloretos $7,25 \mathrm{gr}$ por litro; glicose $0,59 \mathrm{gr}$ por litro. Reação de Pandy, forte opalescência; reação de Weichbrodt, opalescência; reação de Nonne, leve opalescência. Reaçăo do benjoim coloidal 00000.02222 .82200 .0 ; reação de TakataAra positiva, tipo floculante. Reações de Wassermann, desvio de complemento para cisticercose, de Steinfeld e reação de floculação de Eagle, negativas (Dr. João B. dos Reis, 10-11-1949). Exame radiologico - O exame radiográfico da coluna vertebral, incluindo os segmentos cervical, dorsal e lombar, em projeções ântero-posterior, lateral e oblíquas, assim como do tórax, revelou: a) cifoscoliose dorsal alta, de curto raio, com o ápice da curvatura em $T_{4}$ e dextro-convexa; b) hemivértebra triangular, correspondente a $T_{4}$, de base direita, articulada com $T_{3}$ e com $T_{5} ;$ c) ausência da 5." costela esquerda; d) 5.4 costela direita, de curto trajeto, fundida à $6 .{ }^{4}$ costela; e) apófise transversa direita de $\mathrm{L}_{\mathbf{1}}$ alongada em relação à esquerda; f) anomalia de tropismo da $5 .^{4}$ articulação interapofisária lombo-sacra. $O$ exame mieloscópico e mielográfico, usando-se como contraste o lipiodol a $20 \%$, revelou parada completa do óleo iodado no nível de transição entre $T_{3}$ e $T_{4}$. Radiografias posteriores demonstraram a existéncia do lipiodol em níveis subjacentes, o que evidenciou a não septação c.mpleta do espaço subaracnóideo (fig. 1). 

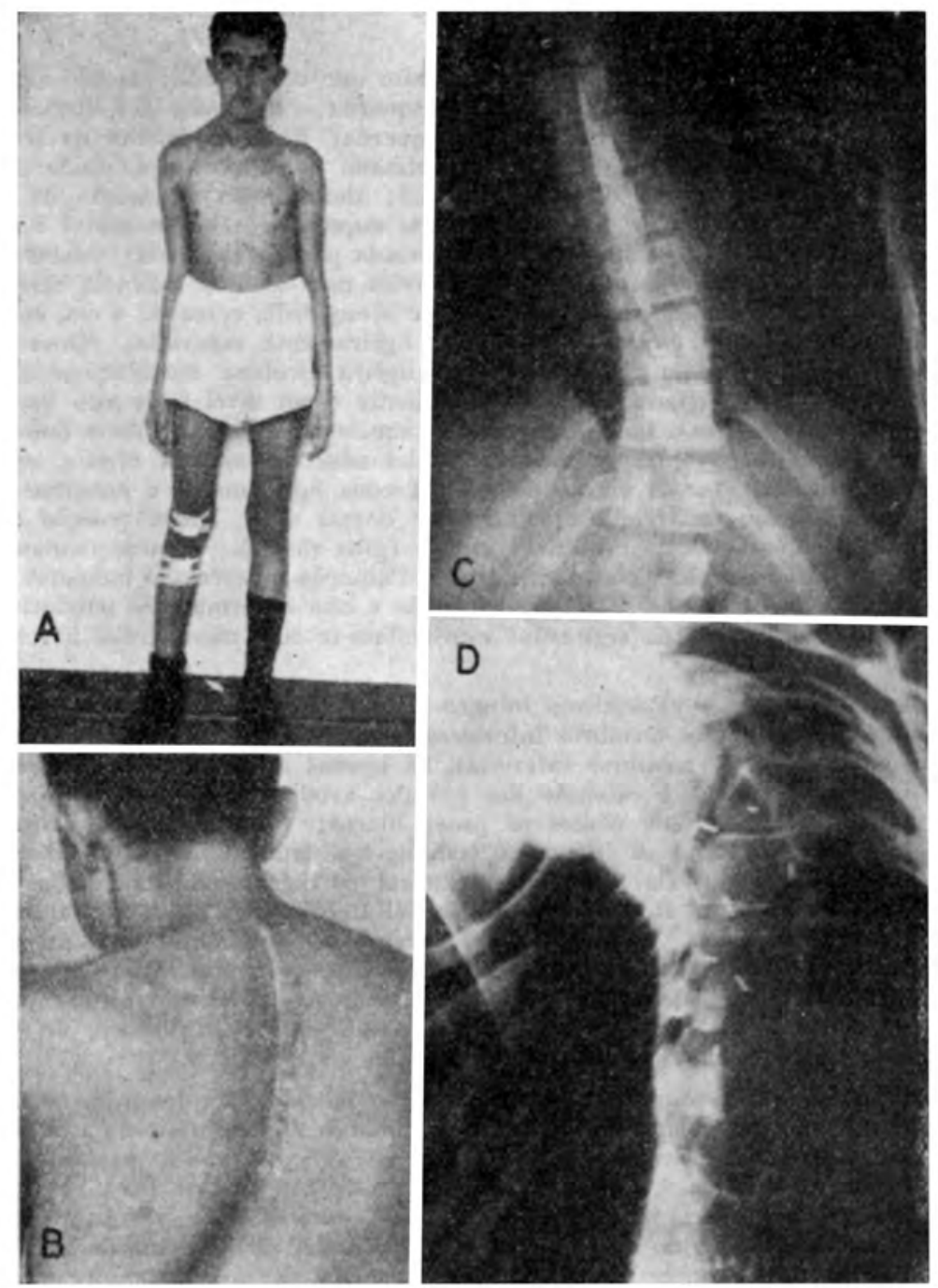

Fig. 1 - Caso L. V. R. Em A, fotografia do paciente após a intervenção. Observar o ombro direito mais elevado que o esquerdo. $\mathrm{Em} \mathrm{B}$, estática vertebral. Cicatriz operatória. Em C, radiografia da coluna cérvico-dorsal, dias depois da mielografia, demonstrando o franqueamento do lipiodol em níveis subjacentes ao bloqueio. Em D, radiografia da coluna dorsal alta, mostrando acentuada cifoscoliose com ápice em $T_{4}$, que se apresenta cuneiforme (anomalia congênita). Imagem dos clips ao nível das raizes seccionadas.

Em vista dos elementos (línicos, liquóricos e radiológicos, firmolı-se o diagnóstico de paraplegia cifoscoliótica e foi decidida a intervenção cirúrgica, a qual foi realizada em 1 de dezembro de 1949 . 
Relatório neurocirúrgico - Paciente em decúbito ventral com suporte sob os ombros e bacia, a fim de facilitar a exposição da região operatória. Incisão semicircular partindo de $\mathrm{C}_{3}$, de concavidade para a direita, seguindo a linha espondílica, atingindo a altura de $\mathbf{T}_{5}$, interessando pele e subcutâneo. Pinçamento e eletrocoagulação dos vasos que sangram. Isolamento com campes. Exposição das apófises espinhosas e lâminas correspondentes. Retirada das apófires espinhosas de $C_{5}$ a $T_{4}$, e lâminas correspondentes, expondo-se o espaço epidural, que era constituído de gordura com aspecto normal. Lateralizou-se então o saco dural, angulado fortemente para a direita e cujo ponto mais crítico correspondia a $\mathbf{T}_{4}$. Iniciou-se então a feitura de um novo leito para a medula e que constituiu na escavação de uma porção dos processos transversos à esquerda, onde correspondia à angulação, bem como dos ligamentos interósseos, dos tubérculos costais e de uma porção correspondente ao colo das costelas. Êste novo leito, que se estendia de $T_{1}$ a $T_{5}$, foi recoberto com oxicel a fim de forrá-lo e abrigar um segmento do saco dural. A transposição da medula para seu novo leito só foi possível mediante a seç̧ão, entre clips, das raizes $\mathrm{T}_{1}$ a $\mathrm{T}_{4}$, bilateralmente, pois, como é obvio, essas raízes mantinham a medula fixa na posição descrita anteriormente. Realizada essa secção, libertou-se o saco dural desta fixação natural, podendo-se realizar sua transposição para o novo leito, retificando-se dessa maneira saco dural e medula. O saco dural foi aberto, visualizando-se a medula, que tinha aparência perfeitamente normal. Parte do lipiodol foi eliminado e a sondagem do canal, para cima e para baixo, foi inteiramente livre. Deliberou-se deixar a dura aberta a fim da descompressão ser mais eficiente. Após hemostasia cuidadosa, o campo operatório foi preenchido por oxicel, para evitar espaço morto. Dando-se por encerrada a intervenção, os planos músculo-aponeuróticos foram suturados em três camadas, com pontos de nỵlon e a pele com sêda preta n. ${ }^{\circ} 2$. Imobilização relativa do tórax e do pescoço.

Evolução - Examinamos o paciente, muito ràpidamente em vista das dôres na região operitória, en 3-12-1949, portanto dois dias após a intervenção. $O$ paciente já conseguia fazer débeis mas perceptíveis movimentos de flexão e extensão dos pés. Recuperação mais ampla da sensibilidade; o enfêrmo diferencia claramente a sensibilidade dolorosa, mesmo nos pés. Dada alta hospitalar ao paciente, sua melhoras foram-se processando aos poucos. Entretanto, surgiram algumas pequenas escaras de decúbito que, após, se cicatrizaram perfeitamente.

No dia 17 de janeiro de 1950 (48 dias após a operação) realizamos novo exame neurológico. O paciente já conseguia ficar de pé, embora necessitando alargar a base de sustentação. Nítido sinal de Romberg. Marcha apenas possível desde que o paciente esteja amparado e se processa de modo espástico e com alargamento da base. Ausência de paralisia em qualquer grupo muscular (exceto de músculos intercostais), embora todos os movimentos dos menbros inferiores se processem com débil energia de contração. Provas de Mingazzini e de Barré francamente positivas. A coordenação muscular, dificultada pelo déficit motor, torna-se mais precária quando é suprimido o contrôle visual. Hipotonia muscular quando o paciente é examinado em decúbito dorsal. Reflexos aquileus exaltados, com trepidações epileptóides; patelares e dos adutores, vivos e assimétricos; mediopúbico revelando maior refletividade dos músculos adutores. Reflexos profundos dos membros superiores, normais. Reflexo cutaneoplantar: à direita, obtém-se franco sinal de Babinski; à esquerda, obtém-se constantemente a resposta em extensão, desde que se excite o bordo lateral do pé, enquanto que a resposta se processa sempre em flexão, ao se excitar o bordo medial. Reflexos cutâneo-abdominais normais. Clono dos pés e rótulas. Automatismo esboçado de ambos os lados. Sensibilidade: ligeira hipoestesia táctil, nos artelhos e plantas dos pés; faixa de anestesia radicular no nível operatório; a sensibilidade artrestésica persiste abolida. Pequenas escaras de decúbito em vias de cicatrização. Neste estado, prescrevemos fisioterapia e reeducação muscular, e paulatinamente as melhorias foram-se acentuando. 
Em 10 de fevereiro de 1950, solicitamos novo exame de líqüido cefalorraquidiano, o qual, a despeito da evidentíssima recuperação clínica, foi encontrado profundamente alterado: punção lombar deitado; pressão inicial 16; pressão final 5, após a retirada de $7 \mathrm{ml}$; após a retirada de $10 \mathrm{ml}$ a pressão caiu a 0 (manômetro de Claude). Formação de retículo fibrinoso. Citometria 14,8 cél. $/ \mathrm{mm}^{3} \quad(98 \%$ de linfócitos e $2 \%$ de eosinófilos); proteínas totais 1,10g/litro; cloretos 7,31 g por litro; glicose $0,48 \mathrm{~g}$ por litro. Reação de Pandy, opalescência; reação de Nonne, leve opalescência. Reação do benjoim coloidal 00000.22222 .00000 .0 ; reação de Takata-Ara positiva, tipo floculante. Reações de Wassermann, desvio de complemento para cistieercose, de Steinfeld e de Eagle, negativas. Prova de Stookey: bloqueio absoluto do canal raquidiano (Dr. João B. dos Reis).

Apesar dêsse bloqueio absoluto do canal raquidiano, as melhoras foram-se processando e se acentuando. Revímo-lo em 5 de abril de 1950, portanto, 4 meses após a intervenção. Já caminhava perfeitamente; neste dia chegou a nos pedir autorização para jogar futebol. O exame neurológico revelou esbôço do sinal de Romberg, desde que a manobra fôsse sensibilizada. Na posição de pé havia exagêro da lordose lombar; a marcha lembrava um pouco a dos miopatas. Fôrça muscular muito satisfatória, sendo negativas as manobras de Mingazzini e de Barré. Tono muscular normal nos membros inferiores. Ataxia sensitiva discreta às provas de calcanharjoelho. Reflexos profundos nos membros inferiores vivos. Esbốço de Rossolimo, no pé esquerdo. Babinski esboçado, inconstante, à esquerda; ausente à direita. Ausência de clono, trepidações ou automatismos. Sensibilidade superficial praticamente normal, com exceção da faixa de anestesia determinada pelas radicectomias. Diminuição da sensibilidade profunda segmentar em ambos os membros inferiores. Cicatrização completa das escaras.

\section{COMENTARIOS}

Vários aspectos merecem ser realçados nesta observação. 0 caráter congênito da cifoscoliose, derivada de um defeito de desenvolvimento, vem atestado por outras manifestações, reveladas, sobretudo, pelo exame radiológico do esqueleto. De fato, como podemos ver em parte pelas figs. 3 e 4, além da cifoscoliose, verificamos uma hemivértebra triangular, correspondendo a $\mathbf{T}_{4}$, de base direita e de tal modo articulada com $\mathbf{T}_{5}$ a dar a impressão de fusão entre ambas. Outras anomalias são registradas pelas chapas radiográficas: enquanto que há ausência da $4 .^{a}$ costela esquerda, a $5 .^{a}$ costela direita, de curto trajeto, acha-se fundida à $6 .^{\mathrm{a}}$ costela. A apófise transversa direita de $L_{1}$ é alongada em relação à esquerda e, ainda, verificamos anomalia de tropismo da 5. articulação interapofisária lombo-sacra. Tais defeitos de desenvolvimento são registrados também na maior parte dos casos semelhan. tes publicados (Dereux e col. ${ }^{6}$, André-Thomas e col. ${ }^{10}$ e Bargelini ${ }^{11}$ ). Heuver e Feld ${ }^{12}$ assinalam um caso de paraplegia por cifoscoliose no decurso de uma moléstia de Recklinghausen, no qual inicialmente se suspeitou da existência de um fibroneurinoma intra-raquidiano como causa da compressão medular. Interessante acentuar, contudo, que, em nosso doente. a cifoscoliose só foi observada poucos meses antes do aparecimento da sintomatologia neurológica medular, coincidindo com um esfôrço extraordinário suportado pela coluna. $O$ aparecimento da anomalia, no entanto, costuma ser muito mais precoce. No doente de André-Thomas e col. ${ }^{10}$, o desvio anormal já era evidente desde a idade de 7 meses. Como em nosso caso, noutro pa- 
ciente estudado por André-Thomas e o casal Sorrel 5, o início da escoliose foi muito mais tardio, apenas com a idade de 15 anos, alguns meses antes do aparecimento da sintomatologia medular.

Desejamos focalizar particularmente a técnica operatória empregada, cujos resultados surpreendentes e rápidos colocam nosso caso entre os de recuperação mais precoce registrados na literatura médica. Inspiramo-nos na técnica de Hyndman, a qual se baseia em verdadeiro transplante da medula para novo leito ósseo formado pela remoção de pedículos, processos transversos das vértebras e cabeças das costelas ao nível do lado côncavo da escoliose. Para facilitar essa transposição, que corresponde a verdadeira verticalização ou retificação da medula, tornou-se necessária a secção de vários pares de raízes nervosas intercostais, que originaram paralisias de ner. vos intercostais e zonas radiculares de hipoestesia, aliás sem maiores conseqüências. Foram retiradas nada menos de sete apófises espinhosas $\left(T_{z} a\right.$ $\mathrm{T}_{4}$ ) e lâminas correspondentes e seccionados quatro pares de raízes nervosas $\left(\mathrm{T}_{1}\right.$ a $\left.\mathrm{T}_{4}\right)$.

O tratamento conservador, por coletes ortopédicos, talha habitualmente. Realmente, vários fatôres colaboram para o insucesso do tratamento ortopédico incruento. Já a própria cifoscoliose determinada por uma vértehra cuneiforme é de redução muito difícil e êsse obstáculo vem acrescido pela impotência motora, pelos distúrbios de esfincteres e pela iminência de desenvolvimento de escaras de decúbito. Da revisão bibliográfica de Pais ${ }^{3}$, que recolheu todos os casos registrados de cifoscoliose na literatura, deduz-se que o método terapêutico que piores resultados proporciona é o do tratamento puramente ortopédico, conservador, por coletes de gêsso. Muito melhores efeitos obtiveram os pacientes submetidos a laminectomia e, entre êstes, a cura foi mais completa e pronta, quando o cirurgião tinha o cuidado de não suturar a dura-máter no encerramento da operação.

Comparando-se o tempo de cura (aproximadamente 2 meses) dos fenômenos de nosso paciente - submetido a uma técnica operatória inédita em nosso meio - com os tempos referidos na mencionada revisão de Pais, salienta-se nosso caso como um dos de recuperação mais rápida na literatura médica. Após a intervenção, desaparecida a fenomenologia neurológica, é aconselhável então o uso do colete ortopédico.

\section{SUMARIO}

Ao que julgam os autores, o caso que ora registram representam o primeiro caso brasileiro de cifoscoliose congênita tratada neurocirìrgicamente. Estudaram inicialmente as diversas doutrinas explicativas do sofrimento medular nessa enfermidade. Insistiram no papel da compressão da medula entre as duas faces da dura-máter, anterior e posterior: a primeira aplicada contra a convexidade óssea e a segunda, fortemente distendida pelas raízes nervosas, contra a face posterior da medula. A maior incidência de fenômenos medulares entre os 15 e 20 anos de vida, época do maior crescimen- 
to do indivíduo, comprova o papel desempenhado, em sua patogenia, pelo estiramento longitudinal da dura-máter, sòlidamente fixada no orifício magno e no sacro. Finalmente, a torção da coluna e a possibilidade de compres. são de vasos sangüíneos, com conseqüentes mielomalácias, deve ser considerada diante de cada caso. Nesses fundamentos baseia-se a indicação da abertura da dura-máter e sua não suturação após a laminectomia. Nos casos da literatura em que a intervenção cirúrgica se limitou à abertura do canal raquidiano, os resultados foram pouco brilhantes.

Registraram os autores a observação de um jovem de 17 anos, que, ano e meio antes, ao suportar a coluna um esfôrço exagerado, começou a apresentar dôres lombares, as quais motivaram a indicação de um colete de gêsso. Entretanto, pouco a pouco, foram-se desenvolvendo sinais de déficit motor e sensitivo nos membros inferiores. Ao exame, foi observada uma paraplegia crural absoluta, sendo possíveis, apenas, pequenos movimentos de flexão e extensão dos grandes artelhos. Reflexos profundos exaltados, trepidação e clono nos membros inferiores; sinal de Bahinski bilateral; hipoestesia táctil, térmica e dolorosa até $\mathrm{T}_{8}$; anestesia profunda nos membros inferiores. Cifose dorsal alta pronunciada, com escoliose dorsal média dextro-convexa e ligeira escoliose dorsolombar sinistro-convexa. 0 exane do líqüido cefalorraquidiano, em punção lombar, revelou bloqueio completo do canal vertebral e líqüido com característica dissociação albumino-citológica. As radiografias demonstraram uma cifoscoliose dorsal alta, dextro-convexa, com ápice em $\mathrm{T}_{4}$; hemivértebra triangular, correspondendo a $\mathrm{T}_{4}$, de base direita articulada em $\mathrm{T}_{3}$ e $\mathrm{T}_{5}$; ausência da $5 .^{a}$ costela esquerda, enquanto que a $5 .^{\mathrm{a}}$ costela direita, de curto trajeto, se achava fundida com a $6 .^{\mathrm{a}}$ costela. Os exames mieloscópicos e mielográficos vieram comprovar o bloqueio, pela parada do lipiodol entre $\mathrm{T}_{3}$ e $\mathrm{T}_{4}$. Decidiu-se então o tratamento neurocirúrgico, cujos tempos essenciais foram os seguintes: retirada das apófises espinhosas e lâminas de $\mathrm{C}_{5}$ a $\mathrm{T}_{4}$; feitura de novo leito ósseo entre $\mathrm{T}_{1}$ e $T_{5}$, para a medula, através da escavação de uma porção dos processos transversos à esquerda, bem como dos ligamentos interósseos, dos tubérculos costais e de uma porção correspondendo ao colo das costelas (êsse leito ósseo foi recoberto com oxicel) ; transposição da medula para seu leito mediante a seç̧ão, entre clips, das raizes $T_{1}$ a $T_{4}$ bilateralmente; abertura da dura-máter e sondagem do canal; fechamento, conservando-se a dura-máter aberta. Dois dias após a intervenção, o paciente já conseguia executar alguns movimentos débeis de flexão e de extensão dos pés. Cêrca de 30 dias depois da laminectomia, o paciente já ficava de pé, amparado 0 exame neurológico, realizado 48 dias após o ato cirúrgico, revelou ausência de qualquer paralisia muscular, embora os movimentos fôssem realizados com diminuição de energia; hiperreflexia profunda, sinal de Babinski à direita e inconstante à esquerda; sensibilidade superficial quase normalizada, persistência do bloqueio e líquor com as características de estase. Não obstante, as melhoras progrediram, de modo que o paciente consegue hoje exercer suas atividades normais. $O$ exame neurológico está normalizado, com exceção de ligeiros distúrbios da sensibilidade profunda. Após revisão bi- 
bliográfica, concluíram os autores que seu paciente representa una das mais rápidas e completas recuperaçōes de paraplegias cifoscolióticas registradas na literatura.

\section{SUMMARY}

Paraplegic syndromes depending on congenital kyphoscoliosis are found very seldom. The authors study the different theories which explain the cord lesion determined by a severe congenital kyphoscoliosis. They emphazise the rôle of the cord compression between the two walls of dural tube: the first applied against the bone convexity and the second strongly pulled by nerve roots against the posterior surface of the cord. The greatest incidence of cord signs is found between the 15th and the 20th year of age, just when the growth of the individual is more rapid. This fact supports the pathogenic rôle of the longitudinal stretching of the dura mater. Finally, the spinal torsion and the possibility of vascular vessels compressions are emphazised.

A case is reported of a young man, 17 years old, who eighteen months before the examination, after an exaggerated physical stress complained of lumbar pains which motivated the use of an orthopedic cast. Slowly the patient developed motor and sensory disturbances in the lower limbs. At examination, an almost complet paraplegy was found. The only movements still possible were slight flexions and extensions of the great toes. Deep reflexes were exaggerated; ankle and knee clonus were present; bilateral Babinski sign. Tactile, pain and thermic hyposthesia up to level of $T_{3}$; absolut deep anesthesia in the lower limbs. Severe high thoracic kyphosis with thoracic medial dextro-convex kyphosis and slight thoraco-lumbar sinistro-convex scoliosis. Complete spinal block on manometric tests, and spinal fluid with albumino-cytologic dissociation. $\mathrm{X}$ ray pictures demonstrated a high thoracic kyphoscoliosis to the right with apex in $\mathrm{T}_{4}$; triangular hemivertebra corresponding to $\mathrm{T}_{4}$, with its right basis articulated with $\mathrm{T}_{3}$ and $\mathrm{T}_{5}$; absence of the 5 th left rib, while the 5 th right rib, short, was fused with the 6 th rib. The lipiodol test showed a blocking hetween $T_{3}$ and $\mathrm{T}_{4}$. Surgical treatment consisted of removal of spinous apophysis and lamina of $\mathrm{C}_{5}, \mathrm{C}_{6}, \mathrm{C}_{7}, \mathrm{~T}_{1}, \mathrm{~T}_{2}, \mathrm{~T}_{3}$ and $\mathrm{T}_{4} ;$ a new bone bed was made for the cord, between $T_{1}$ and $T_{5}$, by excavation of a portion of transverse processes at left and of interosseous ligaments, costal tubercles and a portion of heads or ribs (this bed was covered with oxycel); displacement of the cord to its new bed after bilateral section of roots $T_{1}, T_{2}, T_{3}$ and $T_{4}$; the dura was opened for inspection and left with no suture; closure of the wound. Two days after operation, the patient was already able to flect and extend the feet. About 30 days later, he was able to stand up with support. Neurologic examination made 48 days after the intervention failed to show any muscular complete paralysis, although all the movements of the lower limbs were weak. The deep reflexes were still exaggerated and Babinski sign was present on the right side but inconstant on the left. Superficial sensation 
was almost normal but deep sensibility was still disturbed. Spinal block was still present until the last examination (70 days after operation), but neurological examination was practically negative. A comparison with reported cases in literature shows that in this patient recuperation was faster and fuller than the great majority.

\section{BIBLIOGRAFIA}

1. Pupo, P. P., Reis, J. B. e Barros, Paulo - Uma complicação rara na moléstia de Friedreich. Comunicação à Seç̧ão de Neuropsiquiatria em 6 outubro 194.1. Rev. Paulista Med., 20:101-102, 1942.

2. Hyndman, O. R. - Transplantation of the spinal cord. The problem of kyphoscoliosis with cord signs. Surg., Gynec. a. Obst., 84:460-464, 1947.

3. Pais, C. - Le paraplegie da cifoscoliosi. Chir. d. Org. di Movinento, 31:29-45 (janeiro-abril) 1947.

4. Rouqués, David, M. e Pautrat, J. - Cit. por Dereux e col. 6 .

5. André-Thomas, Sorrel, E. e Mme. Sorrel-Déjerine - La paraplégic scoliotique (à propos d'un cas suivi d'autopsie). Presse Méd., 41:1542-1547 (outubro 7), 1933.

6. Dereux, J. Billet, H., Desorgher, G. e Goullard, X. - Paraplégie cypho-scoliotique. Á propos d'un cas suivi d'autopsie. Rev. Neurol., 79:3-13 (janeiro) 194.7.

7. Cit. por Dereux e col. 6 .

8. Chavany, J. A. - Comentário ao trabalho de Dereux, "Paraplegie cypho-scoliotique", publicado in Rev. Neurol., 77:208, 1945.

9. Barré, J. A., Coste, F. e Sicard, A. - Paraparésie cyphoscoliotique et troubles de l'èquilibration. Rev. Neurol., 75:151-152 (junho) 1943.

10. André-Thomas, Oberthur e Puech, P. - Paraplégie scoliotique guérie par laminectomie suivie de l'ouverture permanente de la dure-mère. Rev. Neurol., 73:150-159 (abril) 1941.

11. Bargellini, D. - Scoliosi congenita con sindrome di compressione midollare. Arch. di Ortopedia, 56:261-267, 1940.

12. Heuyer, G. e Feld, M. - Paraplégie par cyphoscoliose au cours d'une maladie de Recklinghausen. Rev. Neurol., 76:25\%-260, 19.4.

Rua Araujo 165, 7.9 andar -- São Paulo, Brasil. 